\title{
Pelatihan Accounting in Marketing Perspective Pada OMNI MBA Program 2020, Insitut Teknologi Bandung (ITB)
}

\author{
Wiwiek Mardawiyah Daryanto \\ Sekolah Tinggi Manajemen IPMI, DKI Jakarta, Indonesia 12750 \\ Author E-mail: wiwiek.daryanto@ipmi.ac.id
}

\begin{abstract}
A B S T R A K
Laporan keuangan merupakan sebuah penggambaran kondisi keuangan suatu perusahaan. Dimana, didalamnya terdapat informasi yang sangat berguna bagi pihak-pihak yang berkepentingan dalam mengambil keputusan. Kendati demikian, masih banyak para pengambil keputusan yang tidak paham akan pentingnya memahami laporan keuangan, termasuk dasar-dasar akuntansi. Mengetahui hal tersebut, Sekolah Bisnis dan Manajemen- Institut Teknologi Bandung (SBM-ITB) bersama MarkPlus pada OMNI MBA Program 2020, membuat pelatihan Accounting in Marketing Perspective guna menciptakan calon manajer pemasaran yang berkualitas. Pelatihan ini berjalan lancar karena antusiasme yang kuat dari para peserta didik. Diharapkan melalui pelatihan ini, peserta didik dapat memahami materi yang disampaikan serta mengaplikasikannya ke dunia kerja.
\end{abstract}

Kata Kunci: Akuntansi, Pemasaran, Laporan Keuangan.

\section{A B S T R A C T}

The financial report is a description of the financial condition of a company. Where, there is information that is very useful for interested parties in making decisions. However, there are still many decision makers who do not understand the importance of understanding financial reports, including the basics of accounting. Knowing this, the School of Business and Management - Bandung Institute of Technology (SBM-ITB) together with MarkPlus at the 2020 OMNI MBA Program, created an Accounting in Marketing Perspective training to create qualified prospective marketing managers. This training went smoothly because of the strong enthusiasm of the students. It is hoped that through this training, students can understand the material presented and apply it to the work field.

Key word: Accounting, Marketing, Financial Statements.

Copyright @ 2020 Authors. This is an open access article distributed under the Creative Commons Attribution License, which permits unrestricted use, distribution, and reproduction in any medium, provided the original work is properly cited. 


\section{PENDAHULUAN}

Sebuah perusahaan selalu membutuhkan laporan keuangan sebagai informasi untuk kepentingan suatu pihak, baik internal maupun eksternal (Sutrisno, 2007). Kasmir (2008) mendefinisikan bahwa laporan keuangan adalah laporan yang menunjukkan kondisi keuangan perusahaan pada saat ini atau dalam suatu periode tertentu.

Dengan adanya laporan keuangan, pihak-pihak yang berkepentingan dapat dengan mudah merancang strategi kedepannya, tak terkecuali bagi manajer pemasaran. Manajer pemasaran membutuhkan informasi komponen biaya; seperti penetapan harga jual produk, penentuan sistem penjualan secara kredit atau tunai, beban komisi penjualan, biaya pemasaran, serta informasi nilai diskon untuk produk tertentu dalam acuan tolak ukur peningkatan volume penjualan.

Meskipun begitu, sebuah studi yang dikemukakan oleh Fournaise Marketing Group (2014), menyatakan bahwa 90,0\% dari 1.200 manajer pemasaran tidak memiliki paham dasar-dasar akuntansi. Oleh sebab itu, lebih dari 80,0\% dari manajer pemasaran kesulitan dalam melaporkan efektivitas bisnis atau strategi yang tepat dari pengeluaran pemasaran, kampanye, dan aktivitas pemasaran mereka terhadap pihak manajemen.

Mencermati permasalahan berikut, Sekolah Bisnis dan Manajemen- Institut Teknologi Bandung (SBM-ITB) berkolaborasi dengan MarkPlus Institute bersama-sama membuat OMNI MBA Program 2020 yang berlangsung dari tanggal 18 September s.d 24 Oktober, 2020. Dari dua belas topik mata kuliah yang terdapat dalam programnya, salah satunya adalah Accounting in Marketing Perspective atau Akuntansi dalam Perspektif Pemasaran dijadwalkan selama 1 hari yaitu 19 September, 2020. Mata kuliah ini dibagi menjadi dua sesi; Sesi 1 09:00 s.d 10: 30 dan Sesi 2 10:30 s.d 12:00 melalui Zoom Meetings. Adapun, materi yang dibahas yakni Analisa Rasio Keuangan pada Sesi 1 dan Analisa Break-Even Point pada Sesi 2. Surat penunjukan penulis sebagai salah satu pembicara pada OMNI MBA Program 2020 dapat dilihat di Gambar 1.

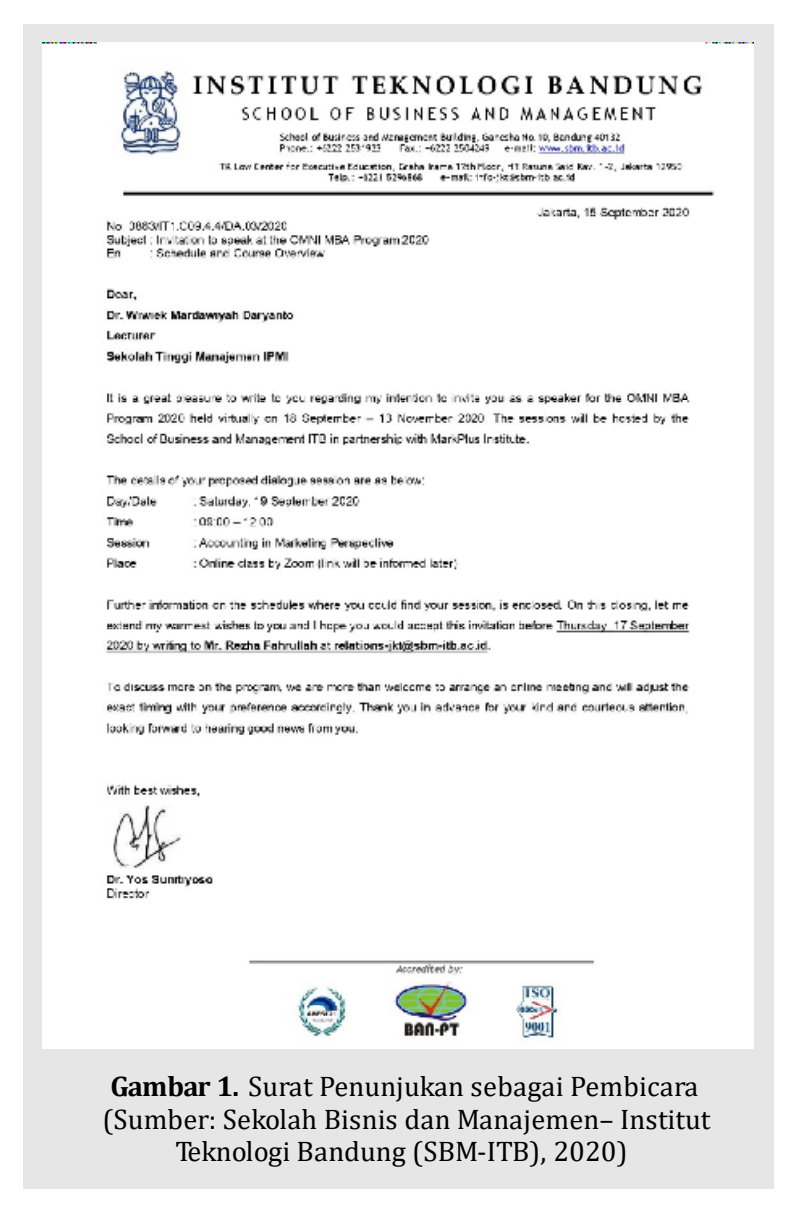

Peserta didik dalam program ini yakni para manager atau direktur yang berasal dari berbagai jenis perusahaan sesuai dengan Tabel 1.

\section{Rasio Keuangan}

Rasio keuangan merupakan sebuah "arithmatical term" yang dapat digunakan untuk menjelaskan hubungan antara dua macam data finansial. Dengan penyederhanaan ini, kita dapat menilai secara cepat hubungan antar pos dan dapat membandingkannya dengan rasio lain sehingga kita dapat memperoleh informasi dan memberikan penilaian (Harahap, 2011).

Analisa ratio keuangan pada dasarnya dapat dilakukan dengan 2 (dua) macam cara perbandingan, yakni:

1. Membandingkan rasio sekarang dengan ratio-ratio dari waktu yang lalu (rasio historis) atau dengan ratio-ratio yang diperkirakan untuk waktu-waktu yang akan datang dari 
perusahaan yang sama.

2. Membandingkan rasio-rasio dari suatu perusahaan dengan rasio-rasio semacam dari perusahaan lain yang sejenis atau industri (rasio rata-rata) untuk waktu yang sama.

Tabel 1. Daftar Peserta Didik Pelatihan Accounting in Marketing Perspective pada Tanggal, 19 September 2020

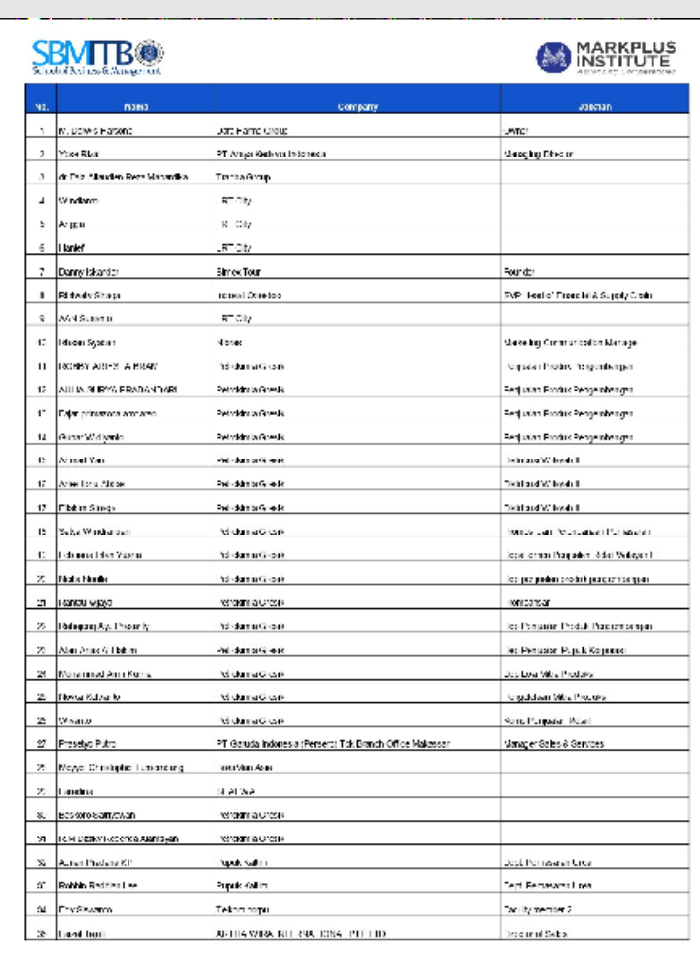

(Sumber: Sekolah Bisnis dan Manajemen- Institut Teknolog Bandung (SBM-ITB), 2020)

Martono dan Agus (2009) mengelompokkan rasiorasio dalam rasio-rasio likuiditas, rasio-rasio leverage, rasio-rasio aktivitas, dan rasio-rasio profabilitas, sebagai berikut:

1. Rasio likuiditas adalah rasio-rasio yang dimaksudkan untuk mengukur likuiditas perusahaan (current ratio, acid test ratio).

2. Rasio leverage adalah rasio-rasio yang dimasudkan untuk sampai berapa jauh aktiva perusahaan dibiayai dengan hutang (Debt to total assets ratio, net worth to debt ratio dan lain sebagainya).

3. Rasio-rasio aktivitas, ialah rasio-rasio yang dimaksudkan untuk mengukur sampai berapa besar efektivitas perusahaan dalam memanfaatkan sumber-sumber dananya (inventory turnover, average collection period dan lain sebagainya)

4. Rasio-rasio profitabilitas, ialah rasio-rasio yang menunjukan hasil akhir dari sejumlah kebijaksanaan dan keputusan-keputusan (profit margin on sales, return on total assets, return on net worth, dan lain sebagainya).

\section{Break-Even Point (BEP)}

Break-even adalah suatu keadaan dimana perusahaan tidak memperoleh laba dan tidak menderita kerugian. Dengan kata lain suatu usaha dikatakan Break-even apabila jumlah penghasilan sama dengan jumlah biaya, atau apabila marginal income, yaitu selisih antara hasil penjualan dengan biaya variabel hanya dapat digunakan untuk menutup biaya tetap.

Menurut Herjanto (2007), analisa Break Even Point (BEP) adalah suatu analisis yang bertujuan untuk menemukan titik dalam kurva biaya pendapatan yang menunjukkan biaya sama dengan pendapatan. Dimana, analisa BEP menyajikan informasi kepada manajemen, sehingga memudahkannya didalam menganalisa faktor-faktor yang mempengaruhi pencapaian laba perusahaan dimasa yang akan datang. Ada dua cara untuk menentukan Break-even, yaitu Teknik Persamaan, dan Pendekatan Grafis.

1. Teknik Persamaan

Laba adalah sama dengan hasil penjualan dikurangi dengan biaya, atau dapat dinyatakan dalam persamaan sebagai berikut:

$Y=c x-b x-a$

dimana: $\quad-y=$ laba

- $c$ = harga jual per satuan

- $x=$ jumlah produk yang dijual

- $b$ = biaya variabel per satuan

- $a$ = biaya tetap

Apabila persamaan tersebut dinyatakan dalam bentuk laporan rugi laba.

2. Pendekatan Grafis

Hasil penjualan $\quad \mathrm{Rp} c \mathrm{x}$

Biaya variabel

$\underline{\mathrm{bx}}-$

Marginal income

Rp cx - bx

Biaya tetap

Laba

$\underline{\mathrm{Rp} y}$ 
Dalam definisi, suatu perusahaan akan Breakeven apabila jumlah penghasilan sama dengan jumlah biaya (laba $=$ nol, $y=0$ ) atau kalau dinyatakan dengan pernyataan adalah sebagai berikut:

$$
\begin{aligned}
& 0=c x-b x-a \\
& c x=b x+a
\end{aligned}
$$

Persamaan tersebut diselesaikan sebagai berikut:

$$
\begin{aligned}
& c x=b x+a \\
& c x-b x=a \\
& X(c-b)=a \\
& X(\text { BREAK - EVEN })=\frac{a}{c-b}
\end{aligned}
$$

Keterangan:

$\mathrm{cx}=\mathrm{bx}+\mathrm{a}$--------hasil penjualan = biaya

$\mathrm{cx}-\mathrm{bx}=\mathrm{a}$--------contribution margin = biaya tetap

Jadi Break-even (dalam satuan produk) adalah biaya tetap dibagi dengan selisih antara harga jual per satuan dengan biaya variabel per satuan. Break-even dalam rupiah penjualan dapat dicari rumusnya dengan cara mengalikan rumus break even dengan c, yaitu harga jual per satuan produk.

$$
\mathrm{c}(\mathrm{xBE})=\frac{(a) c}{c-b}=\frac{a c}{c-b}=\frac{a}{1-b / c}
$$

Jadi rumus perhitungan Break-even dalam rupiah penjualan, adalah:

$$
\text { Break Even }(\mathrm{Rp})=\frac{a}{1-b / c}
$$

Catatan :

1 - b/c disebut marginal income ratio atau margin ratio, yaitu hasil bagi marginal income dengan hasil penjualan.

\section{TUJUAN DAN MANFAAT PELAKSANAAN}

Adapun tujuan dari terlaksananya kegiatan pelatihan Accounting in Marketing Perspective ini, adalah untuk memberikan pemahaman bagi peserta didik, bahwa akuntansi dan pemasaran merupakan sebuah korelasi. Dimana, dari hasil laporan keuangan seorang akuntan memberikan pengaruh terhadap keputusan sebuah perusahaan baik keputusan produksi, maupun keputusan untuk memasarkan suatu produk. Oleh karena itu, penyeimbangan perspektif pemasaran dengan akuntansi dalam aktivitas pemasaran sangat diperlukan untuk menciptakan pemasar yang akuntabel serta akuntan yang responsif untuk mencapai tujuan bisnis perusahaan.

Sedangkan, manfaat dari pelaksanaan pelatihan Accounting in Marketing Perspective bagi para peserta didik, tak lain adalah, sebagai berikut:

1. Memahami prinsip dasar dan tujuan dari akuntansi;

2. Memahami laporan keuangan, serta rasiorasio keuangan yang berkaitan dengan penjualan;

3. Memiliki keterampilan dalam menentukan Break Even Point (BEP) sebagai patokan dasar perencanaan penjualan perusahaan; serta

4. Memiliki keterampilan dan pengetahuan dalam menganalisis komponen biaya terkait dengan pemasaran.

\section{METODA PELAKSANAAN}

Pelatihan Accounting in Marketing Perspective dilakukan via Zoom Meetings; yang dibagi menjadi dua sesi yakni Sesi 1 09:00 s.d 10: 30 tentang Rasio Keuangan dan Sesi 2 10:30 s.d 12:00 tentang Analisa Break Even Point (BEP). Pelatihan ini dirancang agar peserta didik dapat memahami secara komprehensif materi yang disampaikan, sehingga dapat dimplementasikan secara aplikatif dalam dunia kerja. Adapun metode pelatihan yang digunakan oleh penulis adalah, sebagai berikut:

1. Pemaparan materi dengan menggunakan power-point;

2. Diskusi serta penyelesaian soal studi kasus terkait materi yang dipaparkan.

\section{HASIL DAN PEMBAHASAN}

Pelatihan Accounting in Marketing Perspective yang berlangsung selama 1 hari terbagi menjadi 2 Sesi secara online ini memberikan hasil yang baik atau terbilang berjalan dengan lancar. Hal ini disebabkan adanya faktor pendukung selama berjalannya pelatihan, yakni antusiasme yang tinggi dari peserta didik untuk memahami hal- 
hal, sebagai berikut:

1. Konsep serta prinsip-prinsip akuntansi terkait pemasaran.

2. Arti penting pembelajaran dan pemahaman akuntansi dalam pengembangan profesi pemasaran.

3. Pentingnya peningkayan mutu profesi pemasaran untuk mencapai tujuan bisnis suatu perusahaan.

Antusisme ini dibuktikan dengan banyaknya pertanyaan yang muncul dari para peserta didik ketika diskusi dalam penyelesaian soal studi kasus terkait akuntansi dalam pemasaran. Gambar 2. merupakan foto kegiatan dengan ke tiga puluh lima peserta didik yang berperan aktif dalam pelatihan Accounting in Marketing Perspective.
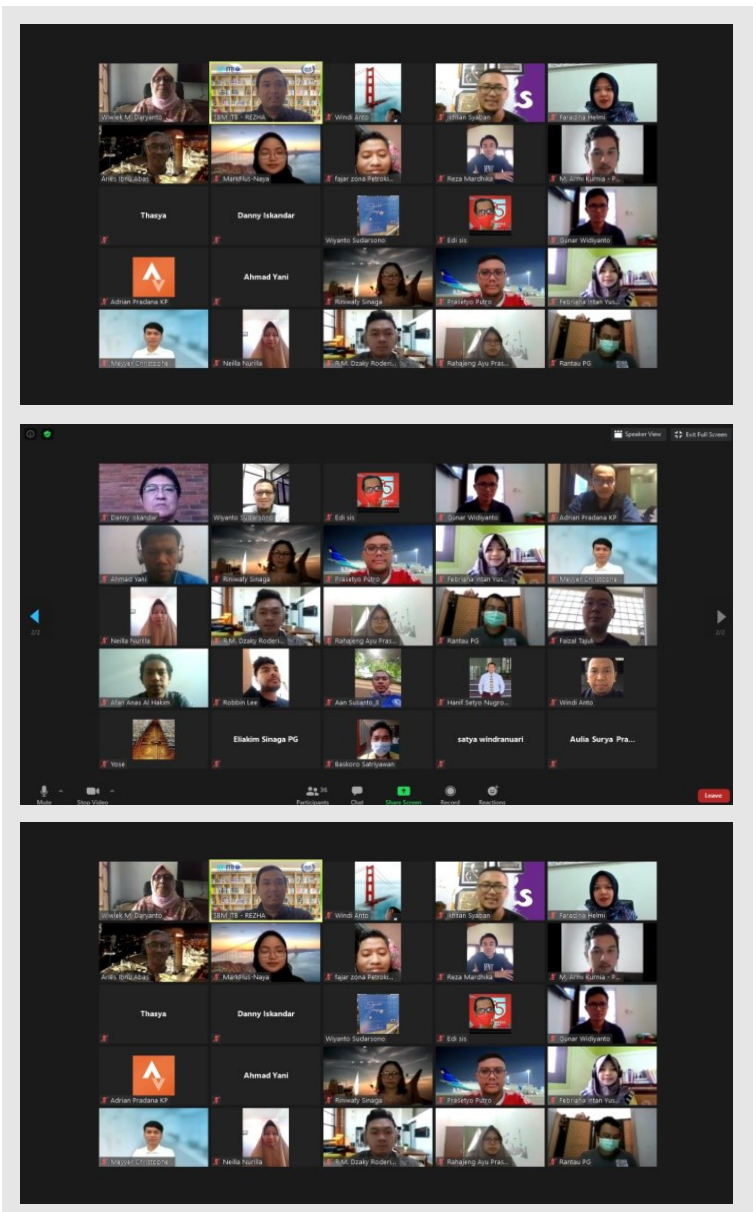

Gambar 2. Foto-foto Kegiatan

Gambar 3. Merupakan sertifikat penghargaan dari Sekolah Bisnis dan Manajemen-Institut
Teknologi Bandung (SBM-ITB) dan MarkPlus kepada penulis atas peran penulis sebagai pendidik dalam Pelatihan Accounting in Marketing Perspective pada Tanggal, 19 September 2020.

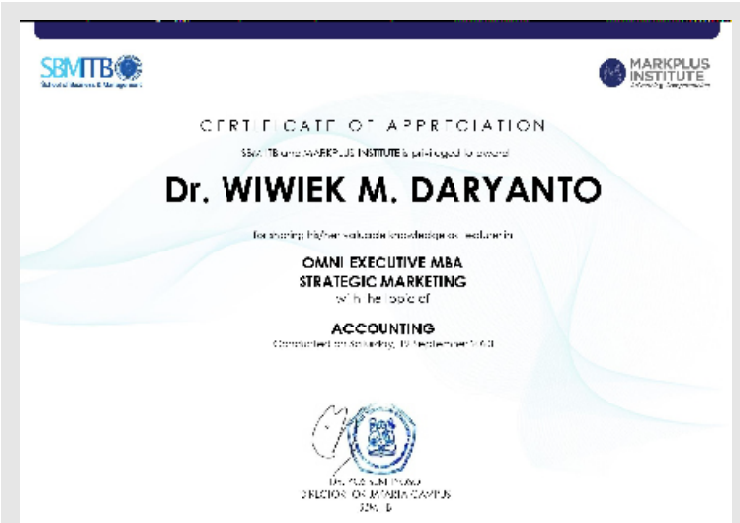

Gambar 3. Sertifikat Penghargaan

(Sumber: Sekolah Bisnis dan Manajemen- Institut Teknologi Bandung (SBM-ITB), 2020)

Tabel 2. Merupakan hasil evaluasi peserta didik terhadap penulis dalam Pelatihan Accounting in Marketing Perspective pada Tanggal, 19 September 2020.

Tabel 4. Hasil Evaluasi Pelatihan terhadap Penulis

\begin{tabular}{lll}
\hline No Nama & $\begin{array}{c}\text { Rata- } \\
\text { Rata }\end{array} \quad$ Nilai \\
\hline 1 Dr. Wiwiek M. Daryanto SE-Ak, M.M, C.MA & 4.35 Luas Biasa
\end{tabular}

Dimana,

1.00 - 1.80 Buruk

$1.81-2.60$ Cukup

2.61 - 3.40 Baik

3.41 - 4.20 Sangat Baik

4.21 - 5.00 Luas Biasa

(Sumber: Sekolah Bisnis dan Manajemen- Institut Teknologi Bandung (SBM-ITB), 2020)

\section{KESIMPULAN DAN SARAN}

Dari hasil pelatihan Accounting in Marketing Perspective dapat disimpulkan bahwa paham akuntansi sangatlah dibutuhkan bagi pihak-pihak yang berkepentingan dalam sebuah perusahaan. Pemahaman akan kondisi keuangan sebuah perusahaan memudahkan pimpinan atau manajer divisi dalam mengambil keputusan yang tepat, serta dapat menghindari kegagalan.

Mengingat pentingnya hal tersebut, selanjutnya 
dibutuhkan pelatihan sejenis namun dalam jangkauan yang lebih luas seperti; perspektif dari fungsi produksi barang atau jasa. Hal ini dikarenakan diperlukannya hubungan yang kuat diantara bagian pemasaran dan produksi. Hubungan tersebut harus selaras dan sejalan, baik dalam fungsi perencanaan, maupun pengendalian.

\section{DAFTAR PUSTAKA}

Sutrisno. (2007). Manajemen Keuangan: Teori, Konsep, dan Aplikasi. Yogyakarta: Ekonisia.

Fournaise Marketing Group. (2014). 90,0\% of Marketers Are Not Trained in Marketing Performance and Marketing RoI. Diakses pada 31 Oktober, 2020, dari: https://www.fournaisegroup.com/ marketers-not-trained-in-marketing-performance-and-roi/.

Herjanto, Eddy. (2007). Manajemen Operasi. Jakarta: Grasindo.

Harahap Sofyan Syafri. (2011), Teori Akuntansi. Edisi Revisi 2011. Jakarta: RajawaliPers.

Agus Harjito, Martono. (2009). Manajemen Keuangan. Edisi1.Yogyakarta: EKONISIA.

Kasmir. (2008). Analisis Laporan Keuangan. Rajawali Pers:Jakarta. 